\title{
Community Structure of Road Associated Avifauna along the Urban Gradient in Mintal, Davao City, Southern Philippines
}

\author{
Christian Yancy A.Yurong', Aileen Grace D. Delima', Leo Manuel B. Estaña ${ }^{2,3}$, Lief Erikson D. Gamalo',2* \& \\ Marion John Michael M. Achondo,2,* \\ ${ }^{1}$ Department of Biological Sciences and Environmental Studies, University of the Philippines Mindanao, Mintal, Davao \\ City, Philippines \\ ${ }^{2}$ Wildlife-Human Interaction Studies, Ecological Research and Biodiversity Conservation Laboratory, University of the \\ Philippines Mindanao, Mintal, Davao City, Philippines \\ ${ }^{3}$ Department of of Mathematics, Physics and Computer Science, University of the Philippines Mindanao, Mintal, Davao \\ City, Philippines \\ *Corresponding authors, email: 1dgamalo@up.edu.ph; mmachondo@up.edu.ph
}

\begin{abstract}
The community structure of avifauna along the urbanization gradient in Mintal, Davao City was surveyed and analyzed. A total of 4,210 individuals from 34 species belonging to 23 families were recorded. Seven species are Philippine endemics and five are introduced species. Correlation and regression analysis showed a positive relationship between increasing vegetation cover with species richness and a negative relationship with abundance. Oppositely, increasing urbanization (increase built-up cover, pedestrian and traffic rate) were observed to have positive relationship to abundance but negative relationship to species richness. Thus, the avian community in the urbanization gradient of Mintal, Davao City follows the general accepted trend that in heavily disturbed areas, species richness is at its lowest while total bird abundance is at its peak. This study also suggests the importance of green spaces with lesser traffic rate in urban landscapes that could support higher avian diversity which includes Philippine endemic species.
\end{abstract}

KEY WORDS Abundance; Birds Diversity; Species richness; Urbanization.

Received 05.05.2020; accepted 18.08.2020; published online 30.09.2020

\section{INTRODUCTION}

Birds are important environmental bioindicators because of their high sensitivity to anthropogenic disturbances, changes and stress in the habitat structure (Kale et al., 2012; Verma \& Murmu, 2015). The species composition, population structure and diversity of an avian community, and even the abundance of one or more significant bird species, can be used to estimate the environmental quality of an area (Padoa-Schioppa et al., 2006). Columba livia Gmelin, 1789, for example, are known to be dependent on urban environment (Shochat et al., 2006) and their presence in a particular area is an indicator that an environment is urbanized or somehow urbanized and developed.

Urbanization changes the avian community structure of a habitat (Blair, 1996; Chace \& Walsh, 2006). Loss and reduction of natural habitat cause local extinction of native birds that are dependent on the native flora and vegetation, while species that are able to adapt and exploit the urbanized habitat survives (Er et al., 2005). This results in a large biomass and dominance of some bird species in 
urban ecosystems but the species richness is reduced (Chace \& Walsh, 2006).

While urbanization has generally a negative effect on biodiversity, some tolerant species may gain benefits from it (DeStefano \& DeGraaf, 2003). For example, species of birds that nests on rocky cliffs and caves may find better nesting sites on walls of residential and commercial buildings (Rolando et al., 1997). It has also been observed that suburban habitats have the most diverse avian community (Verma \& Murmu, 2015). Along the urban-rural gradient, in places where disturbance is at an intermediate level, species richness is typically expected to reach its peak than compared to the two extreme habitats (Blair, 1996; Connell, 1978; McKinney, 2002).

In relation to urbanization, construction of roads directly causes habitat loss, destruction, and fragmentation of existing ecosystems and local landscape (Coffin, 2007). Roads also has severe effects on avian populations such as increased mortality rate due to road collisions, and changes in ecological conditions such as alterations to light, moisture, hydrology, and background noises (Benítez-López et al., 2010; Coffin, 2007; van der Ree et al., 2011). However, roads are reported to attract some birds due to food availability, reduced predation pressures, and offers warm surface and street lights which helps conserve their metabolic energy (Morelli et al., 2014).

This study can provide lists of avian species which can tolerate or can be attracted by roads in an urban area, and underlines the importance of road characteristics that might affect its community structures. Currently, there are few studies conducted on the community of birds associated in urban roads in the country, by knowing the factors affecting the birds, this could provide significant contribution for the enhancement of wildlife conservation coupled with effective urban planning in an expanding urban area in Southern Philippines.

This study aims to determine the community structure of road associated avifauna and its relation to changing levels of disturbance along the urban gradient in the growing metropolis of Davao City. Specifically, this study aims: to characterize urban bird community structures in terms of richness, abundance and diversity, and to determine the relationship of urbanization variables with respect to avian abundance, richness and diversity.

\section{MATERIAL AND METHODS}

\section{Study area}

Mintal, located northwest of Metro Davao City, Philippines is an urban barangay which occupies a land area of 768.21 hectares accommodating a total population 13,227 according to the last 2015 Census (PSA, 2019). Mintal is a category 3 urban barangay defined as a barangay which has five or more establishments with a minimum of ten employees and has five or more facilities within the two-kilometer radius from the barangay hall (PSA, 2019).

Figure 1 shows a map of the study site in Mintal, Davao City (coordinates; 7.0887, 125.5075). It can be observed that the eastern portion of Mintal is highly urbanized where urban structures are heavily clustered and few vegetation is present. Urban facilities such as parks, public markets, department stores, hospital, fire station, and etc. are located in this area. It can also be observed that the urbanization level gradually decreases from east to west direction of Mintal, where urban structures and houses becoming less in number and less clustered, and vegetation gradually increasing in density and cover.

\section{Avian survey methodology}

Bird surveys were conducted between the months of December 2018 to April 2019. A total of 8 surveys for each transect lines, totaling 16 bird surveys (including both morning and afternoon surveys), were done.

Point transect method was used to survey the avian species richness and diversity in the area. In this method, observers traveled along the transect, which is situated along the roads, while stopping in predefined points and recording all birds that were seen and heard for a predetermined amount of time of five minutes. Two 3,600 m roads in Mintal that exhibits an urbanization gradient, shown in Figure 1, were selected as the transect sites with 19 sampling points in each transect following the suggested minimum distance of $200 \mathrm{~m}$ between each sampling points (Gregory et al., 2004).

Location of sampling points were predetermined by using Google Earth. The first sampling 


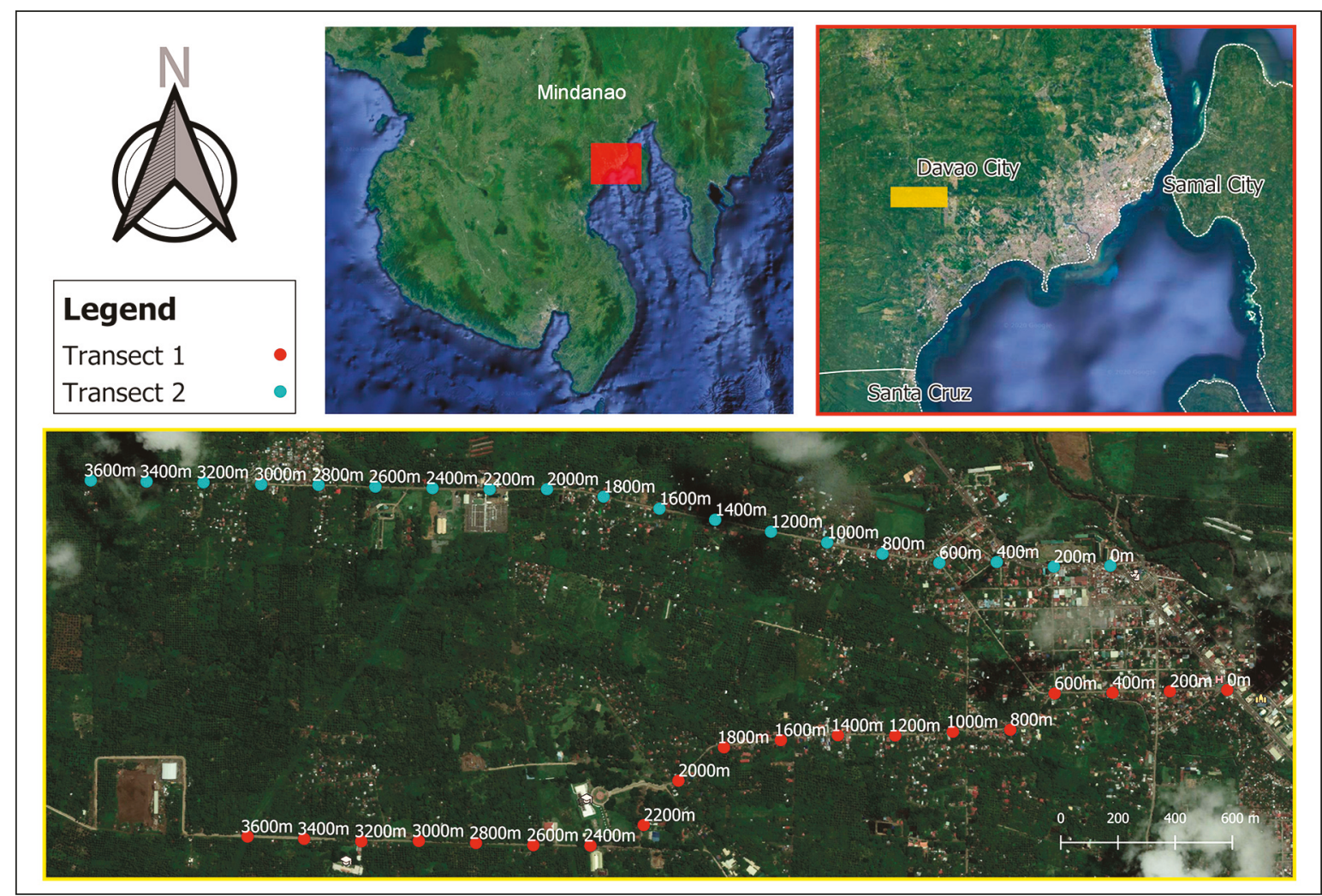

Figure. 1. Map of the study site with the sampling points across two transect sites (modified from Google Earth, 2019).

point is in $0 \mathrm{~m}$, using the distance measurement tool of Google Earth, the next sampling points, which are $200 \mathrm{~m}$ apart from each other, were located until the last point. Morning survey of birds were conducted 30 minutes after sunrise between 6:30AM - 8:00AM, and late afternoon surveys between 5:00PM - 6:00PM when bird activities are in its peak (Billy et al., 2000). Five-minute counts were conducted in each sampling points. All birds that were seen, with the help of binoculars, and heard within the estimated $30 \mathrm{~m}$ radius were recorded (Verma \& Murmu, 2015). After 5 minutes in a sampling point, all activities were stopped and observers moved on to the next sampling point where the next observations were conducted. This was repeated until the last sampling point in a transect.

Bird surveys are commonly designed to start early in the morning when bird activity is highest until mid-morning when bird activity starts to decline (Billy et al., 2000; Gregory et al., 2004). This leads to bird encounters tending to be higher on sampling points sampled earlier than on sampling points sampled later. The opposite effect could be expected for afternoon survey, since bird activity in the afternoon peaks at time before dawn (Billy et al., 2000). There is now a sampling bias based on time. Therefore, to eliminate the time bias in this study, transects that were revisited were surveyed starting from the other end of the transect going in the opposite direction of the first surveys (Billy et al., 2000).

Moreover, considering the 3,600 m length of each road transect, aside from time bias, an observation bias based on fatigue may also occur when surveying a very long transect. To address this concern in this study, instead of surveying the whole transect in one go, each transect sites were divided into two separate surveys instead. The first part of the transect starting from $0 \mathrm{~m}$ to $2,000 \mathrm{~m}$ sampling points were sampled (including morning and afternoon surveys) on the first day while the remaining 2,200 $\mathrm{m}-3,600 \mathrm{~m}$ sampling points were sampled on a different day. After a transect is sampled in the $0 \mathrm{~m}-3,600 \mathrm{~m}$ direction, the succeeding surveys on a same transect were conducted after at least two 
weeks have passed. Transect revisits were sampled by going in the opposite direction of the first surveys starting from the $3,600 \mathrm{~m}$ to $2,200 \mathrm{~m}$ sampling points on the first day and the remaining 2,000 $\mathrm{m}-0 \mathrm{~m}$ sampling points were sampled on a next day.

Guide books "A Guide to the Birds of the Philippines" by Kennedy et al. (2000) and "A Naturalist's Guide to the Birds of the Philippines" by Tañedo et al. (2015) were used as field guide for confirming the identification of bird species in this study. The International Union for Conservation of Nature and other relevant publications were used as the basis for avian distribution and conservation status.

\section{Environmental variables}

Percent cover of vegetation, which covers all types of herbaceous, shrubby and/or arboreal vegetation, within the $30 \mathrm{~m}$ radius from each sampling points were estimated and recorded (Villegas \& Zavala., 2010) by using a free image processing software ImageJ (Schneider et al., 2012). Built-up cover of urbanization density within the $30 \mathrm{~m}$ radius of each sampling point was also estimated and recorded (Villegas \& Zavala, 2010). This includes buildings, houses, roads and any urban related structures. By using Google Earth, a map screenshot of the latest satellite image of each sampling points was imported. The imported images were processed using ImageJ (Schneider et al., 2012) to measure the percent cover of vegetation or built-up density around $30 \mathrm{~m}$ radius of the sampling point.

Pedestrians that passed by or in-standby within the $30 \mathrm{~m}$ radius within each sampling point during the bird surveys were recorded (Villegas \& Zavala, 2010) by a different observer. Just like the pedestrian rate, any vehicle that passed by during the 5 minutes bird survey was recorded simultaneously (Villegas \& Zavala, 2010). Pedestrian and vehicle rates were all recorded by a single observer. This includes all types of vehicles from motorcycles up to 6 to 8 -wheeler utility vehicles. Bicycle are excluded for this variable and is recorded as a pedestrian instead since it does not generate noise and disturbance as much as vehicles.

\section{Data analysis}

Avian diversity of each sampling points across all transects were measured by using the Shannon-
Weiner Diversity Index. Moreover, to estimate the number of species in the sampling sites, Jackknife 1 rarefaction analysis was done. Pearson's correlation test was used to analyze the association of the distance from the urban core on avian abundance, richness, evenness and diversity. Moreover, the effects of environmental and disturbance variables (vegetation cover, urban density, pedestrian rate, and traffic rate) to avian abundance and species richness were measured and analyzed using simple linear regression analysis.

\section{RESULTS AND DISCUSSION}

\section{Community structure of urban birds}

A total 4,210 individuals of birds belonging to 34 bird species from 23 different families were recorded and identified. Seven species were identified as Philippine endemics namely: Phapitreron brevirostris Tweeddale, 1877, Dicaeum australe (Hermann, 1783), Copsychus mindanensis (Boddaert, 1783), Arachnothera flammifera Tweeddale, 1878, Bolbopsittacus lunulatus (Scopoli, 1786), Loriculus philippensis (Müller, 1776), and Rhipidura nigritorquis Vigors, 1831. Five are identified as introduced species: Acridotheres cristatellus (Linnaeus, 1766), Passer montanus (Linnaeus, 1758), Geopelia striata (Linnaeus, 1766), Lonchura oryzivora (Linnaeus, 1758) Columba livia Gmelin, 1789 (Gonzalez, 2006). Moreover, almost all species recorded during the study are of Least Concern except for Lonchura oryzivora or Java Sparrow which is categorized as Vulnerable by the International Union for the Conservation of Nature (IUCN, 2019).

Jackknife 1 rarefaction analysis (Fig. 2) showed an estimate of 38 species that can be found in Mintal, Davao City. This means that $89.47 \%$ of the estimated total species were observed during the study, predicting that more species could be present in the area than the actual species count. Species richness is expected to reach its peak in areas where disturbance is still in intermediate level due to changes in landscapes resulting to habitat diversity and heterogeneity (Blair, 1996; Connell, 1978; McKinney, 2002). The area exhibits a mosaic of different habitat types as seen in the map (Fig. 1) which may be the reason for the high species count. 


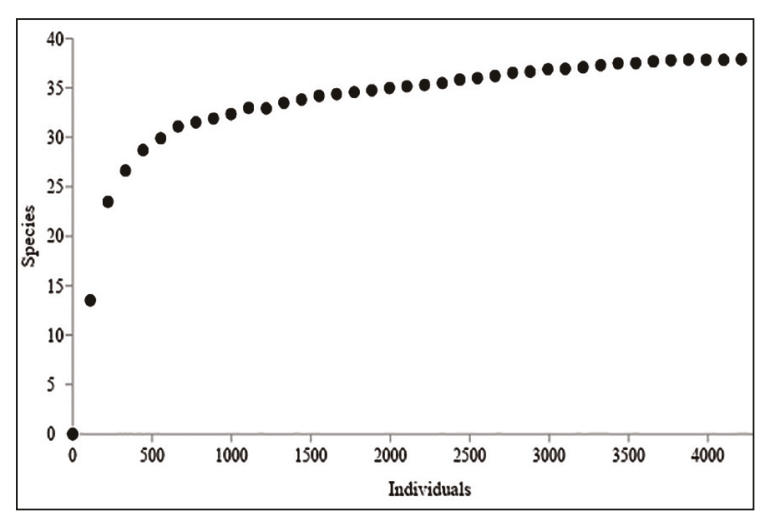

Figure. 2. Jackknife 1 individual-based rarefaction curve of avian species which shows a total of 38 estimated species that can be found in Mintal, Davao City.

In terms of the diversity, Shannon-Weiner's Index of Diversity (2.435) showed lower value when compared to the calculated maximum diversity (3.526). Considering the high species count of 34 , the low diversity index measured in Mintal can be attributed by the low value of species evenness (0.3358) and high abundance of some few species detected. Out of 4,210 individuals of birds recorded in the area, only six species contribute to about $75.9 \%$ of the total avian population. These species are: Passer montanus, Aplonis panayensis (Scopoli, 1783), Pycnonotus goiavier (Scopoli, 1786), Cinnyris jugularis (Linnaeus, 1766), Columba livia, and Dicaeum australe. The P. montanus in particular solely contributes to about $30 \%$ of the total abundance (Fig. 3).

Passer montanus is the most successful introduced species of birds in the Philippines being widely spread and found in nearly every human inhabited island in the country (Gonzalez, 2006; Kennedy et al., 2000). Columba livia on the other hand is one of the most common bird that can be found on heavily urbanized areas such as on business districts of cities (Kark et al., 2007; Tryjanowski et al., 2015). These two species are predominantly granivores, foraging on any seeds which can be found on the ground and can also feed on insects when necessary (Kennedy et al., 2000). Moreover, P. montanus and $C$. livia are known scavengers and will feed on any food left or thrown by humans in urban areas. These two species are heavily associated to human settlements and activities and are considered as bio-indicators of disturbance and urbanization (Gonzalez, 2006; Shochat et al., 2006).
Resources in disturbed and urbanized areas are limited due to urbanization and its structures (Chace \& Walsh, 2006). Natural habitat types are destroyed and replaced by urban structures such as roads, buildings, and houses while native flora is either removed or displaced by garden plants and introduced flora (Chase \& Walsh, 2006). A lot of species are dependent on such resources and incapable of adapting to urban pressures, and are forced to relocate to adjacent areas where resources are still available. This causes significant reduction and/or extirpation of several species' populations in highly urbanized and disturbed environments. Consequently, some species are able to adapt and utilize urban resources making their population persist on urban environments while a very few species have become very dependent on urban resources making their population completely dominating the urban communities (Shanahan et al., 2014).

\section{Community changes along the urbanization gradient}

Correlation analysis showed an increase in community diversity when going towards the less disturbed end of the urban gradient, showing a positive linear relationship $(r=0.685)$ between the two parameters. Having less species means that there are less enemies to compete for an abundant urban food resource which causes very high density of very few species of birds in highly urbanized ecosystems (Shochat et al., 2010). As observed, there was an increasing trend in the number of species from the urban core $(\mathrm{r}=0.4884)$. According to Chase \& Walsh (2006), urbanization tend to select for birds that are generalists, granivorous, aerial insectivores and cavity nesting species which results to lower species richness in urban avian communities dominated by few species which are often introduced. The highest bird density and abundance, P. montanus, C. livia and A. panayensis, was recorded on the sampling points or closest to the urban core. Notice that two of these species, $P$. montanus and $C$. livia, are introduced and granivorous species and the other one, A. panayensis, is an efficient generalist (Kennedy et al., 2000). These species also generally decrease in their abundance along the gradient.

Another possible reason for the low species richness in the urban core is biotic homogenization. 
During homogenization, local flora will be replaced by the same introduced ornamental plant species (McKinney, 2006). This limits the survival of species of birds that are dependent on native flora for nesting and feeding. Several studies on the relationship between urban avifauna and flora already found evidence of positive correlation between native flora with native avifauna, and the positive correlation between introduced ornamental flora with introduced avifauna (Daniels \& Kirk-Patrick, 2006; Emlen, 1974; Mills et al., 1989). This means that in urban areas where vegetation is very low, and if present it is mostly composed of exotic ornamental plants, only species who can utilize introduced resources have the ability to thrive, which are also mostly generalist and introduced species.

\section{Effect of environmental variables to species richness and abundance}

Among the environmental variables tested in this study, the highest regression value $\left(\mathrm{R}^{2}\right)$ for species richness (0.4046) and bird abundance
(0.65343) was the traffic rate, suggesting that traffic could be the main factor that affects avian abundance and richness in the area (Tables 1, 2). Traffic is the primary source of noise pollution in urban environments. Noise pollution from cars as well as some urban sources can mask acoustic signals made by birds (Barber et al., 2010; Gil \& Brumm, 2014; van der Ree et al., 2011). Signals such as mating calls and warning calls will be poorly perceived by birds which can cause for them incapability to reproduce or vulnerability to predators (Gil \& Brumm, 2014). Several studies have already found evidence of species in urban areas that have adapted to the noise pollution by altering the amplitude, frequency, duration, and timing of their calls (Bergen \& Abs, 1997; Brumm \& Zollinger, 2011; Parris \& Schneider, 2009; Schuster et al., 2012; Verzijden et al., 2010; Wood \& Yezerinac, 2006). Increase in car and traffic density in the area is a direct effect of urbanization and disturbance in the area. Therefore, urbanization is still the main force that affects the avian community's species richness and abundance.

In contrast, the lowest measured $\mathrm{R}^{2}$ value for

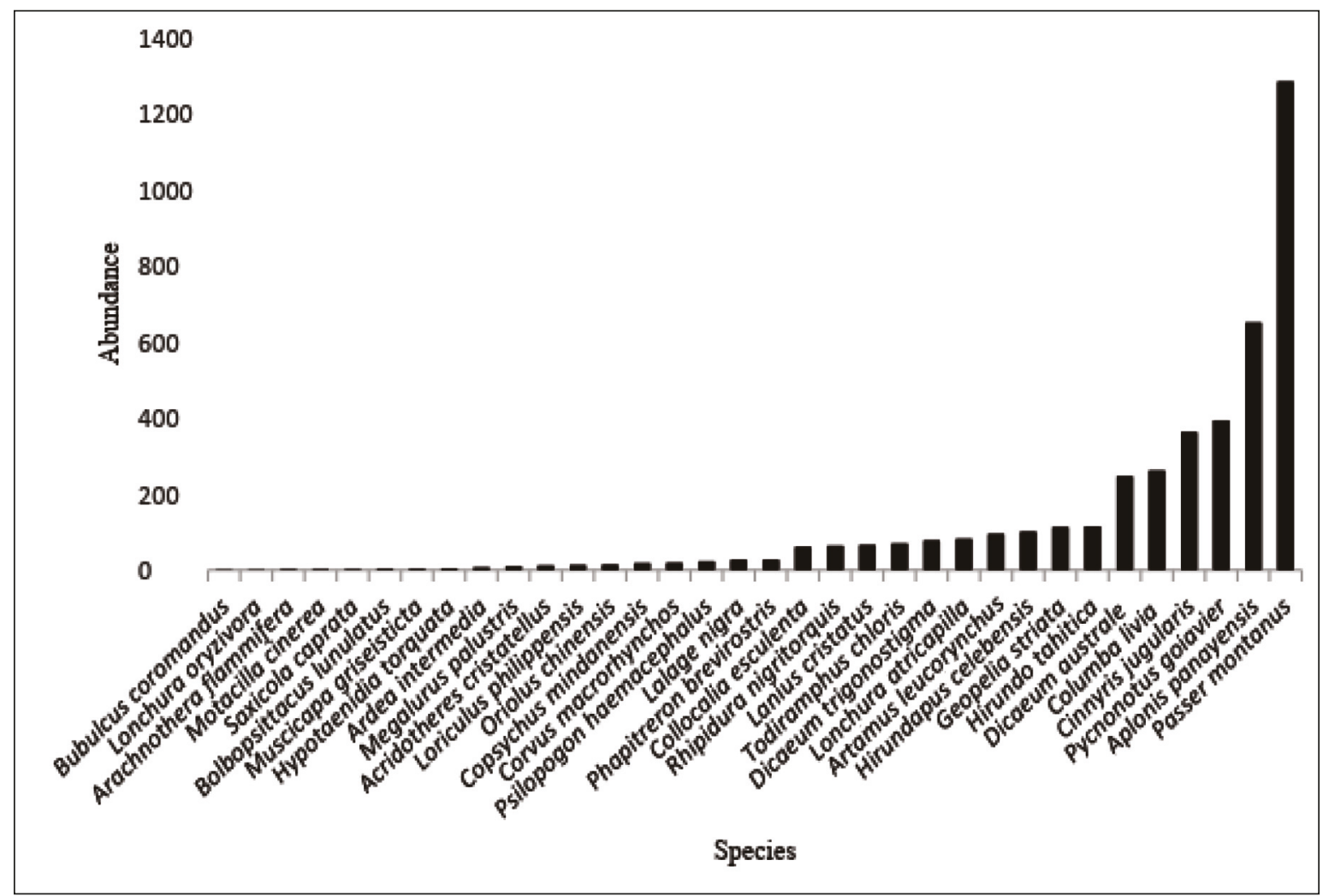

Figure. 3. Abundances of the avian species recorded in Mintal, Davao City. 
both species richness $(0.17398)$ and abundance $(0.23765)$ was from pedestrian rate. The measured $\mathrm{R}^{2}$ values indicates that there is a weak linear relationship between species richness or abundance of birds to increasing pedestrian rate in Mintal. In urban areas, birds typically are less sensitive and can tolerate human presence better than in rural areas and natural areas (Rander, 2008). However, according to Clucas \& Marzluff (2012), habituation of birds to human presence may differ between different places. In their study, they discovered that discouraging behavior of humans towards birds made birds warier to human presence. Nevertheless, human presence still generally affects birds in urban areas especially when nearby feeding or nesting areas. Increased urbanization, which is correlated with increased human visitation and disturbance, causes decreased reproductive success on birds through desertion of eggs, decreased hatching success, decreased ability to feed young, and decreased parental attendance (Chase \& Walsh, 2006).

Aside from car density and traffic rate, the urban structures and vegetation cover variables almost have the same values of $\mathrm{R}^{2}$ measured for species richness (urban density $=0.30048$, vegetation cover $=0.31991$ ) and abundance (urban density $=0.46722$, vegetation cover $=0.46406$ ). This is because the loss of vegetation is directly caused by increasing urbanization. Urbanization directly causes loss, destruction and fragmentation of natural habitats (Chace \& Walsh, 2006; Fuller et al., 2010;
Shanahan et al., 2014) which means that the amount of urban structures and urbanization in an area could be affected by the lost and displaced vegetation and natural habitat. The amount of urban structures and vegetation cover have the exact opposite effects to a community's species richness and abundance. Bird abundance is very high in highly urbanized areas while species richness is in its lowest however, as urbanization decreases and vegetation increases, species richness of the community increases while total abundance of birds decreases (Chace \& Walsh, 2006; Seress \& Liker, 2015).

\section{CONCLUSIONS}

Avian community in the urbanization gradient of Mintal, Davao City follows the general accepted trend that in heavily disturbed areas, species richness is at its lowest while total bird abundance is at its peak. However, our result strengthens the fact that in an urban environment, green spaces and lesser traffic positively support avian diversity which includes the Philippine endemic species. This highlights the need to support the existence of urban green spaces with high vegetation complexity during urban planning. Though the result of this study observed the possible urban factors that pressures avian richness and diversity in a changing urban gradient, the various responses of different birds' species in urban environment need further understanding.

\begin{tabular}{|lllllll|}
\hline Variables & \multicolumn{3}{c}{ Species Richness } & \multicolumn{5}{c|}{ Abundance } \\
\cline { 2 - 7 } & coefficient & $\mathrm{R}^{2}$ & P-value & coefficient & $\mathrm{R}^{2}$ & P-value \\
\hline Vegetation cover & 0.0889 & 0.31991 & 0.00022 & -1.5687 & 0.46406 & $2.51 \mathrm{E}-06$ \\
Urban structures & -0.0836 & 0.30048 & 0.00037 & 1.5276 & 0.46722 & $2.25 \mathrm{E}-06$ \\
Traffic Rate & -0.0153 & 0.4046 & $1.77 \mathrm{E}-05$ & 0.2855 & 0.65343 & $8.39 \mathrm{E}-10$ \\
Pedestrian Rate & -0.0967 & 0.17398 & 0.00918 & 1.6565 & 0.23765 & 0.00191 \\
\hline
\end{tabular}

Table 1. Individual Linear Regression Analysis Values between species richness and abundance with Different Environmental Variables. 


\begin{tabular}{|c|c|c|c|}
\hline Scientific Name & Common Name & Abundance & $\begin{array}{c}\text { Relative } \\
\text { Abundance }\end{array}$ \\
\hline Bubulcus coromandus (Boddaert, 1783) & Eastern Cattle Egret & 1 & 0.00023753 \\
\hline Lonchura oryzivora (Linnaeus, 1758) & Java sparrow & 1 & 0.00023753 \\
\hline $\begin{array}{l}\text { Arachnothera flammifera Tweeddale, } \\
1878\end{array}$ & $\begin{array}{l}\text { Orange-tufted } \\
\text { Spiderhunter }\end{array}$ & 2 & 0.000475059 \\
\hline Motacilla cinerea Tunstall, 1771 & Grey Wagtail & 2 & 0.000475059 \\
\hline Saxicola caprata (Linnaeus, 1766) & Pied Bush Chat & 2 & 0.000475059 \\
\hline Bolbopsittacus lunulatus (Scopoli, 1786) & Guaiabero & 3 & 0.000712589 \\
\hline Muscicapa griseisticta (Swinhoe, 1861) & Grey-streaked Flycatcher & 3 & 0.000712589 \\
\hline Hypotaenidia torquata (Linnaeus, 1766) & Barred Rail & 4 & 0.000950119 \\
\hline Ardea intermedia Wagler, 1829 & Intermediate Egret & 6 & 0.001425178 \\
\hline Megalurus palustris Horsfield, 1821 & Striated Grassbird & 10 & 0.002375297 \\
\hline Acridotheres cristatellus (Linnaeus, 1766) & Crested Myna & 11 & 0.002612827 \\
\hline Loriculus philippensis (Müller, 1776) & $\begin{array}{l}\text { Philippine Hanging } \\
\text { Parrot/Colasisi }\end{array}$ & 12 & 0.002850356 \\
\hline Oriolus chinensis Linnaeus, 1766 & Black-naped Oriole & 13 & 0.003087886 \\
\hline Copsychus mindanensis (Boddaert, 1783) & Philippine Magpie Robin & 17 & 0.004038005 \\
\hline Corvus macrorhynchos Wagler, 1827 & Large-billed Crow & 18 & 0.004275534 \\
\hline Psilopogon haemacephalus (Müller, 1776) & Coppersmith Barbet & 22 & 0.005225653 \\
\hline Lalage nigra (Forster, 1781) & Pied Triller & 26 & 0.006175772 \\
\hline Phapitreron brevirostris Tweeddale, 1877 & Short-billed Brown Dove & 26 & 0.006175772 \\
\hline Collocalia esculenta (Linnaeus, 1758) & Glossy Swiftlet & 60 & 0.014251781 \\
\hline Rhipidura nigritorquis Vigors, 1831 & Philippine Pied Fantail & 63 & 0.014964371 \\
\hline Lanius cristatus Linnaeus, 1758 & Brown Shrike & 65 & 0.01543943 \\
\hline Todiramphus chloris (Boddaert, 1783) & Collared Kingfisher & 69 & 0.016389549 \\
\hline Dicaeum trigonostigma (Scopoli, 1786) & $\begin{array}{l}\text { Orange-bellied } \\
\text { Flowerpecker }\end{array}$ & 77 & 0.018289786 \\
\hline Lonchura atricapilla (Vieillot, 1807) & Chesnut Munia & 81 & 0.019239905 \\
\hline Artamus leucorynchus (Linnaeus, 1771) & $\begin{array}{l}\text { White-breasted } \\
\text { Woodswallow }\end{array}$ & 94 & 0.022327791 \\
\hline Hirundapus celebensis (Sclater, 1865) & Purple Needletail & 100 & 0.023752969 \\
\hline Geopelia striata (Linnaeus, 1766) & Zebra Dove & 112 & 0.026603325 \\
\hline Hirundo tahitica Gmelin, 1789 & Pacific Swallow & 114 & 0.027078385 \\
\hline Dicaeum australe (Hermann, 1783) & Red-keeled Flowerpecker & 246 & 0.058432304 \\
\hline Columba livia Gmelin, 1789 & Rock Dove & 261 & 0.061995249 \\
\hline Cinnyris jugularis (Linnaeus, 1766) & Olive-backed Sunbird & 362 & 0.085985748 \\
\hline Pycnonotus goiavier (Scopoli, 1786) & Yellow-vented bulbul & 393 & 0.093349169 \\
\hline Aplonis panayensis (Scopoli, 1783) & Asian Glossy Starling & 650 & 0.154394299 \\
\hline Passer montanus (Linnaeus, 1758) & Eurasian Tree Sparrow & 1284 & 0.304988124 \\
\hline \multicolumn{2}{|l|}{ Total } & 4210 & 1 \\
\hline
\end{tabular}




\section{ACKNOWLEDGEMENTS}

We would like to thank the Office of Research, University of the Philippines Mindanao for the funding, the Local Government Unit of Mintal for the support of this study. Moreover, we would also like to thank the following persons for the assistance during the sampling and identification: Lourd Lenno Flores, Marissa Pasaol and Kemuel Libre, Jr.

\section{REFERENCES}

Barber J.R., Crooks K.R., \& Fristrup K.M., 2010. The costs of chronic noise exposure for terrestrial organisms. Trends in ecology \& evolution, 25:180-189. https://doi.org/10.1016/j.tree.2009.08.002.

Benítez-López A., Alkemade R. \& Verweij P.A., 2010. The impacts of roads and other infrastructure on mammal and bird populations: a meta-analysis. Biological conservation, 143: 1307-1316. https://doi.org/ 10.1016/j.biocon.2010.02.009

Bergen F. \& Abs M., 1997. Etho-ecological study of the singing activity of the blue tit (Parus caeruleus), great tit (Parus major) and chaffinch (Fringilla coelebs). Journal fur Ornithologie, 138: 451-468.

Billy C.J., Jones M. \& Mardsen S., 2000. Bird Surveys: Expedition Field Techniques. BirdLife International, Wellbrook Court, Cambridge.

Blair R.B., 1996. Land use and avian species diversity along an urban gradient. Ecological applications, 6: 506-519. https://doi.org/10.2307/2269387

Brumm H. \& Zollinger S.A., 2011. The evolution of the Lombard effect: 100 years of psychoacoustic research. Behaviour, 148: 1173-1198. https://doi.org/ $10.2307 / 41445240$

Chace J.F. \& Walsh J.J., 2006. Urban effects on native avifauna: a review. Landscape and urban planning, 74: 46-69. https://doi.org/10.1016/j.landurbplan. 2004.08.007

Clucas B. \& Marzluff J.M., 2012. Attitudes and actions toward birds in urban areas: human cultural differences influence bird behavior. The Auk, 129: 8-16. https://doi.org/10.1525/auk.2011.11121

Coffin A.W., 2007. From roadkill to road ecology: a review of the ecological effects of roads. Journal of transport Geography, 15: 396-406. https://doi. org/10.1016/j.jtrangeo.2006.11.006

Connell J.H., 1978. Diversity in tropical rain forests and coral reefs. Science, 199: 1302-1310. https://doi. org/10.1126/ science.199.4335.1302

Daniels G.D. \& Kirkpatrick J.B., 2006. Does variation in garden characteristics influence the conservation of birds in suburbia? Biological Conservation, 133: 326-335. https://doi.org/10.1016/j.biocon.2006.06. 011

DeStefano S. \& DeGraaf R.M., 2003. Exploring the ecology of suburban wildlife. Frontiers in Ecology and the Environment, 1: 95-101. https://doi.org /10.1890/ 1540-9295 (2003) 001[0095: ETEOSW] 2.0.CO;2

Emlen J.T., 1974. An urban bird community in Tucson, Arizona: derivation, structure, regulation. The Condor, 76: 184-197. https://doi.org/10.2307/1366729

Er K.B.H., Innes J.L., Martin K. \& Klinkenberg B., 2005. Forest loss with urbanization predicts bird extirpations in Vancouver. Biological Conservation, 126: 410-419. https://doi.org/10.1016/j.biocon.2005.06. 023

Fuller R.A., Tratalos J., Warren P.H., Davies R.G., Pepkowska A. \& Gaston K.J., 2010. Environment and biodiversity, in: Dimensions of the sustainable city. Springer, London, 75-103. https://doi.org10.1007/ 978-1-4020-8647-2_4

Gil D. \& Brumm H., 2014. Acoustic communication in the urban environment: patterns, mechanisms, and potential consequences of avian song adjustments, in: Avian Urban Ecology. Oxford University Press, Oxford, 69 pp. https://pure.mpg.de/pubman/item/ item_2181917_7

Gonzalez J.C., 2006. Impact of Introduced Birds in the Philippines. Journal of Environmental Science and Management, 9: 66-79.

Google Earth. 2019. [WWW Document] Mintal, Davao del Sur, Philippines. Google Earth. Available at ohttps://earth.google.com/web/@7.08413465,125.48 941255,143.32805593a,5686.8922525d,35y,0h,45t,0 $\mathrm{r} /$ data=ChUaEwoLL2 cvMXRqeWw3ZmYYAiABKAIoAg. [Date accessed 02 May 2019].

Gregory R.D., Gibbons D.W. \& Donald F.P., 2004. Bird census techniques. In: Ecological Census Techniques. A Handbook. Cambridge University Press, pp. 1735.

IUCN 2019. [WWW Document] Java Sparrow. Available at https://www.iucnredlist.org/species/22719912/ 131809903 [Date accessed: 04 July 2019].

Kale M., Dudhe N., Kasambe R., Chakane S. \& Bhattacharya P., 2012. Impact of urbanization on avian population and its status in Maharashtra State, India. International Journal of Applied Environmental Sciences, 7: 59-76. http://www.ripublication.com/ ijaes. htm

Kark S., Iwaniuk A., Schalimtzek A. \& Banker E., 2007. Living in the city: can anyone become an 'urban exploiter'? Journal of Biogeography, 34: 638-651. https://doi.org/10.1111 / j.1365-2699.2006.01638.x

Kennedy R., Gonzales P., Dickinson E., Miranda H. \& Fisher T., 2000. A guide to the birds of the Philippines, Oxford University Press, Oxford. 
McKinney M.L., 2002. Urbanization, Biodiversity, and Conservation: The impacts of urbanization on native species are poorly studied, but educating a highly urbanized human population about these impacts can greatly improve species conservation in all ecosystems. Bioscience, 52: 883-890. https://doi.org/ 10.1641/0006-3568(2002)052[0883:UBAC" 2.0.CO;2

McKinney M.L., 2006. Urbanization as a major cause of biotic homogenization. Biological conservation, 127: 247-260. https://doi.org/10.1016/j.biocon.2005.09. 005

Mills G.S., Dunning Jr J.B. \& Bates J.M., 1989. Effects of urbanization on breeding bird community structure in southwestern desert habitats. The Condor, 91: 416428. https://doi.org/10.2307/1368320

Morelli F., Beim M., Jerzak L., Jones D. \& Tryjanowski P., 2014. Can roads, railways and related structures have positive effects on birds?-A review. Transportation Research Part D, 30: 21-31. https://doi.org/ 10.1016/j.trd.2014.05.006

Padoa-Schioppa E., Baietto M., Massa R. \& Bottoni L., 2006. Bird communities as bioindicators: The focal species concept in agricultural landscapes. Ecological indicators, 6: 83-93. http://dx.doi.org/10.1016/j.ecolind.2005.08.006

Parris K.M. \& Schneider A., 2009. Impacts of traffic noise and traffic volume on birds of roadside habitats. Ecology and society, 14: 29. http://www.ecologyandsociety.org/vol14/iss1/art29/

Philippine Statistics Authority, 2019. [WWW Document] POPCEN 2015. Available at https://psa.gov. ph/tags/popcen-2015. [Date accessed 20 January 2019).

Randler C., 2008. Risk assessment by crow phenotypes in a hybrid zone. Journal of ethology, 26: 309-316. https:// doi.org/10.1007 / s10164-007-0062-z

Rolando A., Maffei G., Pulcher C. \& Giuso A., 1997. Avian community structure along an urbanization gradient. Italian Journal of Zoology, 64:341-349. https://doi.org/10.1080/11250009709356221

Schneider C.A., Rasband W.S. \& Eliceiri K.W., 2012. NIH Image to ImageJ: 25 years of image analysis. Nature methods, 9: 671-675. https://doi.org/10. 1038/nmeth. 2089

Schuster S., Zollinger S.A., Lesku J.A. \& Brumm H., 2012. On the evolution of noise-dependent vocal plasticity in birds. Biology letters, 8: 913-916. https://doi.org/10.1098/rsbl.2012.0676

Seress G. \& Liker A., 2015. Habitat urbanization and its effects on birds. Acta Zoologica Academiae Scientiarum Hungaricae, 61: 373-408. https://doi.org/10. 17109/AZH.61.4.373.2015
Shanahan D.F., Strohbach M.W., Warren P.S. \& Fuller R.A., 2014. The Challenges of Urban Living. In: Avian urban ecology: Behavioural and physiological adaptations, Oxford University Press, Oxford, 3-20. https://doi.org/10.1093/acprof:osob1/978019

Shochat E., Lerman S. \& Fernández-Juricic E., 2010. Birds in urban ecosystems: population dynamics, community structure, biodiversity, and conservation. Urban ecosystem ecology, 55: 75-86. https://doi. org/10.2134/agronmonogr55.c4

Shochat E., Warren P.S., Faeth S.H., McIntyre N.E. \& Hope D., 2006. From patterns to emerging processes in mechanistic urban ecology. Trends in ecology \& evolution 21: 186-191.https://doi.org/10.1016/j.t ree. 2005.11.019

Tañedo M., Hutchinson R., Constantino A. \& Constantino T., 2015. A Naturalist's Guide to the Birds of the Philippines, John Beaufoy Publishing, Oxford, England.

Tryjanowski P., Skórka P., Sparks T.H., Biaduń W., Brauze T., Hetmański T., Martyka R., Indykiewicz P., Myczko Ł., Kunysz P. \& Kawa P., 2015. Urban and rural habitats differ in number and type of bird feeders and in bird species consuming supplementary food. Environmental Science and Pollution Research, 22: 15097-15103. https:// doi.org/10.1007/s11356015-4723-0

van der Ree R., Jaeger J.A., van der Grift E.A. \& Clevenger A.P., 2011. Effects of roads and traffic on wildlife populations and landscape function: road ecology is moving toward larger scales. Ecology and society, 16: 48. https:// doi.org/10.5751 / ES-03982160148

Verma S.K. \& Murmu T.D., 2015. Impact of environmental and disturbance variables on avian community structure along a gradient of urbanization in Jamshedpur, India. PloS one, 10 (7). https://doi. org/10.1371/journal.pone. 0133383

Verzijden M.N., Ripmeester E.A.P., Ohms V.R., Snelderwaard P. \& Slabbekoorn H., 2010. Immediate spectral flexibility in singing chiffchaffs during experimental exposure to highway noise. Journal of Experimental Biology, 213: 2575-2581. https://doi.org/10.1242/ jeb.038299

Villegas M. \& Garitano-Zavala Á., 2010. Bird community responses to different urban conditions in La Paz, Bolivia. Urban ecosystems, 13: 375-391. https://doi. org/10.1007/s11252-010-0126-7

Wood W.E. \& Yezerinac S.M., 2006. Song sparrow (Melospiza melodia) song varies with urban noise. The Auk, 123: 650-659. https://doi.org/ 10.1642/ 0004-8038(2006) 123 [650:SSMMSV] 2.0.CO;2 